\title{
Clinical and genetic heterogeneity in early onset cerebellar ataxia with retained tendon reflexes
}

\author{
A Filla, G De Michele, F Cavalcanti, A Perretti, L Santoro, F Barbieri, G D'Arienzo, \\ G Campanella
}

\begin{abstract}
A clinical and genetic study was performed on 20 patients affected by early onset cerebellar ataxia with retained tendon reflexes (EOCA). Mean age at onset was $8 \cdot 8(\mathrm{SD} 6.0)$ years. The frequency distribution of age of onset significantly differed from the normal distribution. Consanguinity rate was $16.7 \%$ and segregation ratio $0 \cdot 164$. As well as ataxia, which was a constant feature, there were signs of involvement of the cortico-spinal tracts and/or peripheral nerves in most patients. Results of neurophysiological studies were not homogeneous, nor were morphological findings of the sural nerve biopsy. The data suggest that EOCA may be genetically and clinically heterogeneous.
\end{abstract}

Harding ${ }^{1}$ described the clinical and genetic features of 20 patients with progressive cerebellar ataxia, developing within the first two decades, and associated with dysarthria, pyramidal weakness and retained or increased knee jerks. In addition to the preservation of tendon reflexes, other features distinguishing it from Friedreich's disease (FD) were a better prognosis and absence of optic atrophy, cardiomyopathy, diabetes mellitus, and severe skeletal deformities. Harding suggested the name early onset cerebellar ataxia with retained tendon reflexes (EOCA) for this entity, which is probably of autosomal recessive inheritance in most cases. After FD, EOCA is the most common of the early onset hereditary ataxias, representing $13.8 \%$ of all index cases. ${ }^{2}$

In this paper we describe clinical, genetic and laboratory findings of 20 EOCA patients. Their features are also compared with those of the EOCA patients described by Harding ${ }^{1}$ and those of a personal series of $70 \mathrm{FD}$ patients ${ }^{3}$ (Filla et al unpublished).

Patients and methods

Two hundred and twenty nine patients with spino-cerebellar degenerations have been observed since 1973 at the Department of Neurology of the Second School of Medicine at the University of Naples. One hundred and twenty four had onset before 20 years. Twenty of them had a clinical picture classifiable as EOCA. Besides early onset, the criteria for this diagnosis were progressive ataxia, retained knee jerks and exclusion of a known aetiology. Patients with hypogonadism or myoclonus were excluded. All patients received a thorough neurological evaluation by at least one of the authors. Progression of the disease was evaluated according to the Inherited Ataxia Progression Scale ${ }^{4}$ (IAPS): Stage 1: asymptomatic affected patient, detected among the siblings and offspring of a known case; Stage 2: symptoms present, but mild; Stage 3: patient needs constant care and cannot work; Stage 4: patient confined to a wheelchair or bed.

Routine blood and urine tests were performed in all cases. EEG, CT scan and ECG were performed in most patients, and neurophysiological investigations and sural nerve biopsy when possible.

The segregation ratio was calculated assuming multiple incomplete ascertainment (Weinberg's "proband" method ${ }^{5}$ ). To investigate genetic heterogeneity, intrafamilial variation of onset age was analysed using the Kruskal-Wallis test. ${ }^{5}$ Onset ages of affected sibs not personally observed were also included, when reliably referred. Departure from normality of the frequency distribution of onset age was tested by Chi-square. ${ }^{6}$

\section{Results}

Twenty patients from 18 families fulfilled the above criteria. All were index cases. Twelve were male and eight female. At the time of the last examination, mean age (SD) was $27 \cdot 7$ $(10.5)$ years, range 16-58. Mean age at onset was $8 \cdot 8(6.0), 2-19$. Mean duration of the disorder was $17 \cdot 3(10 \cdot 8), 2-41$. The last two values refer to 19 patients; in the remaining case the age of onset was before 20 years, but could not be established exactly.

Genetic aspects Table 1 shows the genetic features of the patients. Five siblings were reported to be affected and they will not be

\section{Table 1}

\begin{tabular}{lc}
\hline \multicolumn{2}{c}{ Genetic data } \\
\hline Families & 18 \\
Affected singletons & 13 \\
$\Longrightarrow \quad$ pairs & 3 \\
triplets & 2 \\
Total number of cases & 25 \\
Healthy siblings & 43 \\
Segregation ratio (Weinberg's method $\left.{ }^{5}\right)$ & $0 \cdot 164$ \\
Consanguineous marriages & $3\left(16 \cdot 7^{\circ}\right)$ \\
\hline
\end{tabular}


Figure Frequency distribution of onset age in 19 patients with early onset cerebellar ataxia with retained tendon reflexes that significantly differed from the normal (Chi-square = 11.16; $d f$ $=4 ; p<0.05)$.

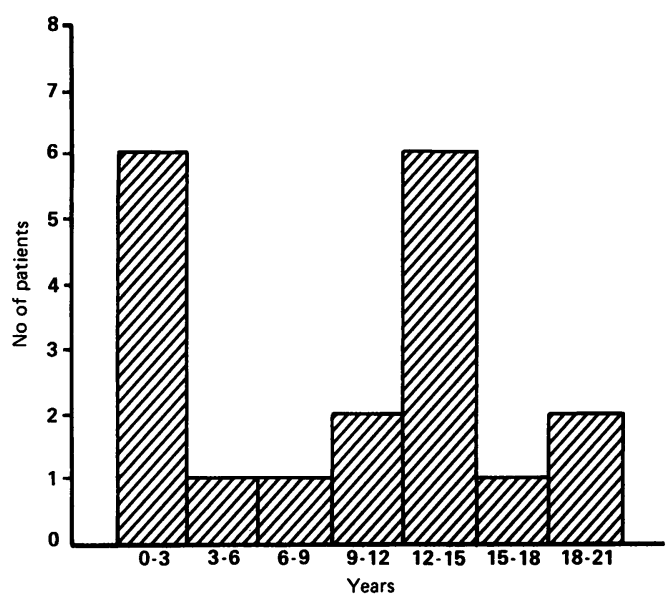

considered further. No instance of similar disease was found in either parents or offspring of the patients. Segregation ratio was $0 \cdot 164$ and its $95 \%$ confidence limits were $0 \cdot 061-0.267$. This value was not significantly different from $0 \cdot 25$, the expected ratio for an autosomal recessive disease (Chi-square $=1 \cdot 75 ; \mathrm{df}=1$ ). Consanguinity rate was $16.7 \%$ and in all cases the parents were first cousins. The KruskalWallis test showed that onset age varied significantly between families ( $S=9.59$; $\mathrm{df}=4 ; \mathrm{p}<0.05$ ).

Clinical features The figure shows the histogram of the frequency distribution of onset age. Two peaks were evident at $0-3$ and $12-15$, and there was a significant departure from normality (Chi-square $=11 \cdot 16 ; \mathrm{df}=4$; $\mathrm{p}<0.05)$.

The most frequent presenting symptom was gait ataxia $(75 \%)$, followed by dysarthria
$(15 \%)$, tremor $(10 \%)$ and lower limb weakness $(10 \%)$.

Table 2 shows the percentage occurrence of clinical features. Signs of cerebellar impairment were present in all patients. Signs of cortico-spinal involvement (lower limb hyperreflexia and/or hypertonia and/or extensor plantar response) were present in different combinations in all but three patients. Clinical findings that suggested peripheral neuropathy (decreased/absent ankle jerks and decreased lower limb vibration sense, sometimes associated with muscle wasting) were observed in six patients. Abnormalities of ocular movements were present in most patients. Impairment of smooth pursuit, dysmetric saccades and fixation instability were the most frequent findings. Scoliosis and/ or pes cavus were present in 14 patients and were mild in almost all of them. Tremor was found in seven patients, usually a combination of intention and postural. Four of these patients also had head titubation. Subnormal intelligence was present in four patients. Seizures occurred in two. Urinary symptoms were present in seven patients, the most common being urgency. Two patients had perioral fasciculations, one torticollis and one dystonic posturing of the hands. Three patients had mild hypoacusia.

Laboratory findings Table 2 summarises the laboratory findings. Routine blood tests did not disclose any major abnormalities; in particular no patient had diabetes. Hexosaminidases A and $B$ were investigated in seven patients though these patients did not form a particular clinical subject and were found to be normal. Electrocardiographs were performed in 12 patients and were abnormal in four. Three had

Table 2 Percentage occurrences of clinical and laboratory findings in early onset cerebellar ataxia with retained tendon reflexes (EOCA) and Friedreich's disease (FD)

\begin{tabular}{|c|c|c|c|}
\hline & $\begin{array}{l}\text { EOCA } \\
\text { Present } \\
\text { study } \\
(n=20)\end{array}$ & $\begin{array}{l}\text { Harding's } \\
\text { study } \\
(n=20)\end{array}$ & $\begin{array}{l}\text { FD } \\
\text { Personal } \\
\text { series } \\
(n=70)\end{array}$ \\
\hline $\begin{array}{l}\text { Gait ataxia } \\
\text { Nystagmus } \\
\text { Abnormal ocular movements } \\
\text { Dysarthria } \\
\text { Dysphagia } \\
\text { Finger-to-nose dysmetria } \\
\text { Lower limb increased tone } \\
\text { Lower limb decreased tone } \\
\text { Increased knee jerks } \\
\text { Decreased (EOCA)/absent (FD) knee jerks } \\
\text { Decreased/absent ankle jerks } \\
\text { Lower limb weakness } \\
\text { Lower limb wasting } \\
\text { Lower limb decreased vibration sense } \\
\text { Extensor plantar response } \\
\text { Scoliosis } \\
\text { Pes cavus }\end{array}$ & $\begin{array}{r}100 \\
70 \\
65 \\
80 \\
20 \\
75 \\
55 \\
30 \\
70 \\
15 \\
30 \\
40 \\
30 \\
85 \\
45 \\
40 \\
35\end{array}$ & $\begin{array}{c}100 \\
40 \\
10^{\star \star} \\
100 \\
5 \\
100 \\
60 \\
-50 \\
0 \\
50 \\
80^{\star} \\
30 \\
55 \\
95^{\star \star} \\
20 \\
50\end{array}$ & $\begin{array}{c}100 \\
27^{\star \star} \\
100^{\star \star} \\
83^{2} \\
27^{\star} \\
96^{\star} \\
1^{\star \star} \\
91^{\star \star} \\
0 \star \star \\
100^{\star \star} \\
100^{\star \star} \\
79^{\star \star} \\
61^{\star} \\
91 \\
74^{\star} \\
93^{\star \star} \\
93^{\star \star}\end{array}$ \\
\hline $\begin{array}{l}\text { Diabetes } \\
\text { Abnormal ECG } \\
\text { Abnormal EEG } \\
\text { Abnormal CT-scan } \\
\text { Abnormal BAEP } \\
\text { Abnormal SSEP } \\
\text { Abnormal MEP } \\
\text { Abnormal MCV } \\
\text { Abnormal SCV } \\
\text { Abnormal sural nerve biopsy }\end{array}$ & $\begin{array}{l}0 \\
33 \\
57 \\
75 \\
75 \\
50 \\
50 \\
46 \\
46 \\
67\end{array}$ & $\begin{array}{c}0 \\
35 \\
-56 \\
- \\
\overline{70} \\
0 \\
33 \\
-\end{array}$ & $\begin{array}{l}13 \\
80^{\star \star} \\
41 \\
36^{\star} \\
92 \\
100^{\star} \\
100 \\
95^{\star \star} \\
100^{\star \star} \\
100\end{array}$ \\
\hline
\end{tabular}


Table 3 Neurophysiological data

\begin{tabular}{|c|c|c|c|c|c|c|c|c|c|}
\hline Case Number & Sex & $\begin{array}{l}\text { Age } \\
\text { (years) }\end{array}$ & $\begin{array}{l}\text { Disease } \\
\text { duration } \\
\text { (years) }\end{array}$ & $\begin{array}{l}\text { IAPS } \\
\text { Stage }\end{array}$ & $M C V$ & $S C V$ & SSEP & $M E P$ & $B A E P$ \\
\hline $\begin{array}{r}1 \\
2 \\
3 \\
4 \\
5 \\
6 \\
7 \\
8 \\
9 \\
10 \\
11 \\
12 \\
13\end{array}$ & $\begin{array}{l}\mathbf{M} \\
\mathbf{M} \\
\mathbf{M} \\
\mathbf{F} \\
\mathbf{M} \\
\mathbf{M} \\
\mathbf{F} \\
\mathbf{F} \\
\mathbf{M} \\
\mathbf{M} \\
\mathbf{M} \\
\mathbf{F} \\
\mathbf{F}\end{array}$ & $\begin{array}{l}27 \\
24 \\
17 \\
44 \\
58 \\
32 \\
23 \\
28 \\
30 \\
18 \\
23 \\
36 \\
29\end{array}$ & $\begin{array}{r}15 \\
12 \\
10 \\
41 \\
48 \\
30 \\
21 \\
26 \\
28 \\
8 \\
21 \\
34 \\
11\end{array}$ & $\begin{array}{l}2 \\
2 \\
2 \\
3 \\
3 \\
2 \\
2 \\
3 \\
3 \\
2 \\
2 \\
4 \\
4\end{array}$ & $\begin{array}{l}\mathbf{N} \\
\mathbf{A} \\
\mathbf{N} \\
\mathbf{N} \\
\mathbf{N} \\
\mathbf{N} \\
\mathbf{A} \\
\mathbf{A} \\
\mathbf{A} \\
\mathbf{A} \\
\mathbf{N} \\
\mathbf{N} \\
\mathbf{A}\end{array}$ & $\begin{array}{l}\mathbf{N} \\
\mathbf{A} \\
\mathbf{N} \\
\mathbf{N} \\
\mathbf{N} \\
\mathbf{N} \\
\mathbf{A} \\
\mathbf{A} \\
\mathbf{A} \\
\mathbf{A} \\
\mathbf{N} \\
\mathbf{N} \\
\mathbf{A}\end{array}$ & $\begin{array}{l}\mathbf{N} \\
\mathbf{A} \\
\mathbf{N} \\
\mathbf{N} \\
\mathbf{N} \\
\mathbf{A} \\
\mathbf{A} \\
\mathbf{A} \\
\mathbf{N P} \\
\mathbf{N P} \\
\mathbf{N P} \\
\mathbf{N P} \\
\mathbf{N P}\end{array}$ & $\begin{array}{l}\mathbf{N} \\
\mathbf{A} \\
\mathbf{N} \\
\mathbf{N} \\
\mathbf{N} \\
\mathbf{A} \\
\mathbf{A} \\
\mathbf{A} \\
\mathbf{N P} \\
\mathbf{N P} \\
\mathbf{N P} \\
\mathbf{N P} \\
\mathbf{N P}\end{array}$ & $\begin{array}{l}\mathbf{A} \\
\mathbf{A} \\
\mathbf{N} \\
\mathbf{N} \\
\mathbf{A} \\
\mathbf{A} \\
\mathbf{A} \\
\mathbf{A} \\
\mathbf{N P} \\
\mathbf{N P} \\
\mathbf{N P} \\
\mathbf{N P} \\
\mathbf{N P}\end{array}$ \\
\hline
\end{tabular}

repolarisation abnormalities, one with supraventricular ectopic beats. Two dimensional and Doppler echocardiography was performed in these four patients and in a further four and was found to be normal. Electroencephalography was performed in 14 patients: eight showed generalised asynchronous slow waves, which were mainly in the theta range and of either low or medium amplitude. In three of these patients the slow waves were more pronounced in posterior regions and sometimes fell in the delta range. CT scan was performed in 16 patients. Twelve showed cerebellar atrophy, which was associated in four cases with brainstem atrophy and with cerebral atrophy in two. Sural nerve biopsy was normal in two patients, and showed moderate to severe loss of large myelinated fibres in four. Results of neurophysiological investigations are reported in table 3.

Progression of the disease Twelve patients $(60 \%)$ were in IAPS stage 2 [mean age (SD) $22.0(5 \cdot 7)], 6(30 \%)$ were in stage $3[37.3$ $(12 \cdot 0)]$, and $2(10 \%)$ were in stage 4 [32:5(4.9)]. Stage 3 was reached within $21.7(12.5)$ years since the onset of the disease. Comparison of clinical and laboratory features between stage 2 and stage 3-4 patients showed higher percentage frequency of extensor plantar response (33 versus 62), skeletal deformities ( 58 versus 88 ) and cerebellar atrophy at CT scan (56 versus 100) in the later stages. Differences were not significant at statistical analysis.

Comparison with Harding's study In Harding's study the mean (SD) onset age, 9.42 $(5 \cdot 23)$, was similar to that in ours, whereas her mean age, 41.85 (14.95), was higher. Furthermore, seven of Harding's patients $(35 \%)$ were not ambulant, compared to only two $(10 \%)$ of ours. In table 2 the clinical findings of our patients are compared with those of Harding's. ${ }^{1}$ She described higher occurrence of lower limb weakness and extensor plantar response and lower occurrence of abnormal ocular movements.

Comparison with FD EOCA patients were compared with a personal series of $70 \mathrm{FD}$ patients $^{3}$ (Filla et al unpublished). Age at onset was later in FD: $11 \cdot 7(4 \cdot 6)(\mathrm{t}=2 \cdot 24 ; \mathrm{df}=87$; $\mathrm{p}<0.05)$. As well as knee jerks and tonus, EOCA also differed from FD with a higher occurrence of abnormal eye movements, finger-to-nose dysmetria, lower limb weakness and wasting, extensor plantar response, and skeletal deformities. Furthermore, abnormalities of peripheral nerve conduction studies and somatosensory evoked potentials were more frequently found in FD, whereas cerebellar atrophy at CT scan was more common in EOCA (table 2). ECG abnormalities in EOCA patients were similar to those found in FD, but less frequent. EOCA patients reached IAPS Stage 3 later after onset than did FD patients, $21 \cdot 7(12 \cdot 5)$ years, versus $7 \cdot 3(4 \cdot 1)$ $t=3.87$ df $=21 ; \mathrm{p}<0.01)$. Although mean (SD) ages of our patients with EOCA and FD, $27 \cdot 7(10 \cdot 5)$ versus $24 \cdot 0(9 \cdot 1)$, were comparable, less EOCA patients were in IAPS stage 4 (10 versus $40 \%$ ).

\section{Discussion}

Harding $^{2}$ described EOCA as the most frequent, after FD, among the early onset inherited ataxias of unknown aetiology. EOCA differs from FD mainly in preservation of knee jerks. Similar cases have been described previously in the literature. Fraser, ${ }^{7}$ Nonne $^{8}$ and Fickler ${ }^{9}$ also gave results of the necropsy examinations; in particular, Fickler's case showed atrophy of the cerebellum, pons and inferior olives.

We describe 20 patients with similar clinical picture, which account for $9 \%$ of all spinocerebellar degenerations and $16 \%$ of the early onset forms observed by us.

In this series we did not find any evidence of dominant transmission. The segregation ratio was $0 \cdot 164$, slightly and not significantly lower than the expected value $(0 \cdot 25)$ for an autosomal recessive disease. Furthermore, the consanguinity rate $(16.7 \%$ versus $2 \%$ in the general population of southern Italy $^{10}$ ) supports the hypothesis of a recessive inheritance. Different hypotheses, as suggested by Harding, ${ }^{1}$ should 
be considered: non-genetic phenocopies, new dominant mutations and $\mathrm{X}$-linked recessive inheritance. The first hypothesis is unlikely, since idiopathic non-genetic cerebellar ataxias usually have later onset. Dominant ataxias have a different age of onset and clinical picture. Although the male/female ratio (12/8) suggests the presence of some $\mathrm{X}$-linked cases, family histories did not show an $\mathrm{X}$-linked recessive inheritance.

The bimodal distribution and the intrafamilial variation of age of onset suggested genetic heterogeneity. ${ }^{5}$ The clinical picture was also heterogeneous. Features of cerebellar impairment of variable degree were present in all the patients. Findings that suggested cortico-spinal involvement were present in the majority of patients, and of peripheral neuropathy in some. Heterogeneity was also evident by examining neurophysiological data. Cortico-spinal and central sensory pathways were impaired in $50 \%$ of patients and central auditory pathways were abnormal in $75 \%$. Peripheral sensory and motor pathways were abnormal in $46 \%$ of patients.

According to the frequency distribution of onset age (fig 1) patients could be divided into two groups with age of onset before and after nine years. However, the clinical and neurophysiological pattern was similar in the two groups. Only extensor plantar response was more frequent in the group with earlier onset (75 versus $18 \%$; Chi-square corrected according to Yates $=4.02 ; \mathrm{p}<0.05)$.

When the present series of patients was compared with that of Harding's ${ }^{1}$ they appeared to be similar. But in the latter, dysarthria and finger-to-nose dysmetria were constant, and lower limb weakness and extensor plantar response more frequent. This discrepancy can be explained by longer disease duration in Harding's patients [32.3 (16.8) versus $17.3(10 \cdot 8)$ ]. Furthermore, $15 \%$ of our patients had decreased knee jerks, versus none in Harding's series.

Patients with FD showed a higher occurrence and severity of most clinical features, and of laboratory findings than those with EOCA. In particular, we did not find evidence of diabetes or echocardiographic evidence of hypertrophic cardiomyopathy in EOCA and the course of that disease was slower.

Even though the clinical picture and progression rate easily distinguished EOCA from FD in most of the patients, individual cases can be misdiagnosed on the basis of the presence or absence of knee jerks. We observed two siblings, not included in the study, with early onset recessive ataxia, one with absent reflexes and hypotonia, fulfilling criteria for a diagnosis of FD, ${ }^{11}$ the other with hyperreflexia and spasticity, who could be classified as EOCA. Molecular genetic studies will help in classifying such patients.

This study was supported by grants from Consiglio Nazionale delle Ricerche and from the Italian Ministry of Health. We thank $\operatorname{Dr} \mathrm{P}$ Strisciuglio for performing hexosaminidase assay and for his helpful suggestions.

1 Harding AE. Early onset cerebellar ataxia with retained arding AE. Early clinical and genetic study of a disorder tendon reflexes: clinical and genetic study of a disorder distinct from Friedreich's
Psychiatry 1981;44:503-8.

2 Harding AE. Classification of the hereditary ataxias and paraplegias. Lancet 1983;i:1151-5.

3 Caruso G, Santoro L, Perretti A, et al. Friedreich's ataxia: electrophysiologic and histologic findings in patients and relatives. Muscle Nerve 1987;10:503-15.

4 Campanella G, Filla A, De Falco FA, Mansi D, Durivage A, Barbeau A. Friedreich's ataxia in the South of Italy: a clinical and biochemical survey of 23 patients. Can J Neurol Sci 1980;7:351-5.

5 Emery AEH. Methodology in clinical genetics. Edinburgh: Churchill Livingstone 1986:37-54; 126-39.

Snedecor GW, Cochran WG. Statistical methods. Ames Iowa: The Iowa State University Press 1967:84-5.

7 Fraser $\mathrm{D}$. Defect of the cerebellum occurring in a brother and sister. Glasgow Med J 1880;13:199-210.

8 Nonne M. Uber eine eigenthümliche familiäre Erkrankungsform des Zentralnervensystem. Arch Psychiat und Nervenkr 1891;22:283-316.

9 Fickler A. Klinische und pathologisch-anatomische Beiträge zu den Erkrankungen des Kleinhirns. Deutsche Zeitschrift für Nervenheikunde 1911;41:306-75.

10 Romeo G, Menozzi P, Ferlini A, et al. Incidence of Friedreich's ataxia in Italy estimated from consanguineous marriages. Am J Hum Gen 1983;5:523-9.

11 Geoffroy G, Barbeau A, Breton G, Lemieux B, Aube M, Leger C, Bouchard JB. Clinical description and Leger C, Bouchard roentgenologic evaluation of patients with

12 Claus D, Harding AE, Hess CW, Mills KR, Murray NMF, Claus D, Harding AE, Hess CW, Mills KR, Murray NMF, Thomas PK. Central motor conduction in degenerative ataxic disorders: a magnetic stimulation
Neurosurg Psychiatry 1988;51:790-5.

13 Hassan NF, Rossini PM, Cracco PQ, Cracco JB. Unexposed motor cortex activation by low voltage stimuli. In: Morocutti C and Rizzo PA, eds. Evoked Potentials: neurophysiological and clinical aspects. Amsterdam: Elsevier, 1985:107-13. 